\title{
Ad Libitum vs. Restricted Fluid Replacement on Hydration and Performance of Military Tasks
}

\author{
Heinrich W. Nolte, Timothy D. Noakes, and Kim Nolte
}

\begin{abstract}
Nolte HW, Noakes TD, Nolte K. Ad libitum vs. restricted fluid replacement on hydration and performance of military tasks. Aviat Space Environ Med 2013; 84:1-7.

Introduction: The primary objective was to evaluate the effect of ad libitum vs. restricted fluid replacement protocol on hydration markers and performance in selected military tasks. The secondary objective was to determine if $300 \mathrm{ml} \cdot \mathrm{h}^{-1}$ could be considered a safe minimum fluid intake under the experimental conditions. Methods: Data were collected simulating a route march over $16 \mathrm{~km}$. There were 57 subjects who participated in the study. Results: The mean pre-exercise body mass of the ad libitum group was $70.4 \pm 13.3$ (SD) $\mathrm{kg}$ compared to $69.3 \pm 8.9 \mathrm{~kg}$ in the restricted group. The mean total fluid intake of the ad libitum group was $2.1 \pm 0.9 \mathrm{~L}$ compared to $1.2 \pm 0.0 \mathrm{~L}$ in the restricted group. The ad libitum and restricted intake groups, respectively, lost a mean of $1.05 \mathrm{~kg} \pm 0.77(1.5 \%)$ and $1.34 \mathrm{~kg} \pm 0.37(1.9 \%)$. Calculated sweat rate was $608 \pm 93 \mathrm{ml} \cdot \mathrm{h}^{-1}$ compared to $762 \pm 162 \mathrm{ml} \cdot \mathrm{h}^{-1}$ in the ad libitum group. Discussion: There were no significant differences for either urine specific gravity (USG) or urine osmolality (UOsm) before or after the exercise. It is not clear whether fluid intake and calculated sweat rates are causally related or explained by their codependence on a third variable; for example, the exercising metabolic rate. Thus, $300 \mathrm{ml} \cdot \mathrm{h}^{-1}$ intake could be considered a current safe minimum water intake for soldiers of similar mass under similar experimental conditions, namely similar exercise durations at equivalent exercise intensities in a moderate, dry climate.

Keywords: hydration status, body mass loss, sweat rate, route march.
\end{abstract}

$\mathrm{W}$ ATER IS THE LARGEST single constituent of the human body and is essential for cellular homeostasis and life. Knowledge of a soldier's water needs is vital in ensuring the health, safety, and performance of military forces, especially in arid conditions in which the provision of water is the critical factor determining ability to sustain military operations (2). Unfortunately, providing an excess of water contributes to the burden of the payloads (mass to be carried) imposed on the dismounted foot soldier, whereas the provision of too little water could have detrimental health consequences. Conversely there are also significant known health risks of consuming too much fluid during exercise such as the development of exercise-associated hyponatremia, sometimes associated with encephalopathy, which can be life threatening (13-15). By determining the optimal water requirements of soldiers, one can ensure their safety, physiological comfort, and performance while optimizing their payload burdens.

Foot soldiers should not usually carry masses in excess of $50 \%$ of their own body mass. These masses have a negative impact on soldier endurance, situation awareness, and the ability to respond quickly and accurately to threats (18). In arid environments water comprises a significant amount of this mass. For example, during deployment in Afghanistan, U.S. soldiers often carried water supplies for missions lasting between 1-3 d, representing $9-10 \mathrm{~kg}$ or in excess of $30 \%$ of their fighting load (18). However, few studies have attempted to establish a safe minimum level of replacement for soldiers during operational activities. Such minimal values would reduce payload requirements while maintaining optimal fluid levels and contribute to overall system performance and mission success. Thus, the primary objective of this study was to evaluate the effect of ad libitum vs. a restricted fluid replacement protocol (fluid intake limited to exactly $300 \mathrm{ml} \cdot \mathrm{h}^{-1}$ ) on selected hydration status markers and military performance measures, and to determine whether the restricted intake could be considered an adequate minimum fluid intake in a group of 57 dismounted infantry soldiers during a simulated route march of $16 \mathrm{~km}$ lasting $4 \mathrm{~h}$.

\section{METHODS}

Subjects

Ethical clearance for this study was obtained from the Research Ethics Committee of the South African Military Health Services of the South African National Defense Force and in accordance with the guidelines of Harriss and Atkinson (8). A request for subjects was put forward to the South African National Defense Force in order to identify soldiers who were experienced and conditioned to route marches with payloads of up to $35 \mathrm{~kg}$. All the subjects (men) were medically fit to participate in the study and none were suffering from any musculoskeletal injuries. Subjects were told they could terminate their participation at any stage without any consequences to their careers. Subjects were required to voluntarily sign an informed consent form before they began the study. The subjects were asked to provide basic demographic

From ERGOnomics TECHnologies, Pretoria, South Africa; UCT/ MRC Research Unit for Exercise Science and Sports Medicine, University of Cape Town, South Africa; and the Department of Biokinetics, Sport and Leisure Sciences, University of Pretoria, South Africa.

This manuscript was received for review in March 2012. It was accepted for publication in August 2012

Address correspondence and reprint requests to: Dr. Heinrich W. Nolte, ERGOnomics TECHnologies, P.O. Box 6264, Pretoria 0001 South Africa; heinrich@ergotech.co.za.

Reprint \& Copyright (C) by the Aerospace Medical Association, Alexandria, VA.

DOI: $10.3357 /$ ASEM.3378.2013 
information for record purposes (age, years of military service, home units). Anthropometric measurements were included to predict fat and muscle percentage distributions using the Drinkwater and Ross method (17). Two days prior to the field study the subjects performed a multistaged shuttle run test to determine predicted maximal oxygen consumption $\left(\dot{V}_{\mathrm{O}_{2 \max }}\right)$ (11). A qualified exercise scientist facilitated a warm-up and stretching session with the subjects prior to performing the test.

\section{Performance Measures}

On the day of the study, performance was recorded during selected military tasks in order to compare the results prior to and upon completion of the 4-h exercise intervention. The participants completed their performance measures simultaneously before and after the conclusion of the exercise intervention. Shooting skills were evaluated on an Electronic Learning Aiming Correction System (IST, Pretoria, South Africa) shooting simulator. All of the subjects were familiar with the use of this simulator since it is used for both initial and ongoing proficiency training. The simulator graded the subjects on three variables of their shooting skills, namely handling, aiming, and trigger control during the task.

An observation task required the subjects to observe, spot, and identify military-related objects that were positioned in the operational area. They needed to identify various objects and report back their location regarding position and distance from where they were standing using standard military protocol. These objects were rotated or replaced with alternatives for the post-exercise observation task. The objects were placed to evaluate the near, far, and peripheral vision of the soldiers. A plastic weapon magazine and dummy metal rounds were used in a task which evaluated fine motor skills. The subjects had to unload and reload a magazine in the fastest possible time. The time was measured from the moment the soldier picked up the loaded magazine until he had completed the unloading and reloading and placed the magazine back on the table.

\section{Exercise Intervention}

Subjects wore standard issue combat dress with military boots, battle jacket, and bush hat. The battle jackets of each of the subjects were similarly packed with mass to the amount of $20 \mathrm{~kg}$. One member of each group carried a Global Positioning System (GPS) and radio to ensure communication and tracking of the groups in terms of speed and direction. The route was $4.0 \mathrm{~km}$ and was repeated four times for a total march distance of $16 \mathrm{~km}$, which took $4 \mathrm{~h}$ to complete. Subjects were randomly assigned to either the restricted $\left(300 \mathrm{ml} \cdot \mathrm{h}^{-1}\right)(N=28)$ or ad libitum intake $(N=29)$ group. Subjects in the ad libitum group were instructed to drink as desired while the restricted group were instructed to finish the $300 \mathrm{ml}$ of water provided to them per hour within each hour of the 4-h intervention. Neither of the two groups was allowed to eat during the study. The ambient temperature, wind speed, barometric pressure, relative humidity, and solar radiation were recorded for the duration of the study (Davis Health Environmental Monitor, South Africa).

\section{Hydration Markers}

Select measures to identify acute changes in hydration status were measured, including body mass and calculated sweat rates. Measures of urine specific gravity (USG) and urine osmolality (UOsm) were included in order to investigate their relationship with acute changes in hydration status as measured by changes in body mass and calculated sweat rates. Sweat rates were calculated from body mass changes as well as fluid intake and urine output during the exercise period. Sweat rates were estimate as follows:

$$
\begin{aligned}
\text { Sweat rate } & =((\text { prebody mass }- \text { postbody mass }) \\
& +(\text { fluid intake }- \text { urine produced })) \\
& \text { /exercise time }
\end{aligned}
$$

Calculated sweat rates were not corrected for respiratory water loss, $\mathrm{CO}_{2}$ loss, or $\mathrm{O}_{2}$ gain. Nude body mass was recorded prior to and upon completion of the route march with an electronic scale (accurate to the nearest $100 \mathrm{~g}$ ). Subjects were provided with towels to dry excess perspiration prior to weighing. Subjects were required to empty their bladders prior to each weighing; these voids were used for USG and UOsm analyses prior to and upon completion of the route march.

\section{Statistical Analyses}

In order to determine which statistical test would be most suited for the comparisons of the ad libitum and restricted intake groups, the differences (paired differences) between the group results were calculated. The distributions (in the form of histograms) of paired differences of all the results were plotted with the number of classes as calculated according to the Rule of Sturge. The normality of this distribution was tested by means of the Shapiro-Wilks' W test. The statistical Rule of Sturge states that the number of classes equals $\mathrm{N} \times 1.4+1$ (Where: $N=$ sample size). The Wilcoxon rank sum test or $t$-tests were used to compare ad libitum and restricted intake results depending on the distribution. A Pearson's product moment correlation coefficient was used to determine relationships between appropriate variables. Statistical significant differences between the ad libitum and restricted intake results were indicated by a $P$-value of less than 0.05 . The statistical analyses were completed using the Statistica ${ }^{\odot}$ software package (21).

\section{RESULTS}

There were 57 subjects who met the selection criteria and volunteered for the study. There were no statistically significant $(P>0.05)$ differences between the years of military experience, body mass, stature, predicted $\dot{\mathrm{V}}_{\mathrm{O}_{2 \max }}$ and predicted percentage body fat and muscle 
for the two groups (Table I). The mean (range) ambient conditions during the study were as follows: dry bulb temperature was $24.6^{\circ} \mathrm{C}(21.0-28.2)$; solar radiation was $599 \mathrm{~W} / \mathrm{m}^{2}$ (257-781); barometric pressure was $641 \mathrm{mbar}$ (640-644); wind speed was $1.9 \mathrm{~km} / \mathrm{h}$ (1.1-2.7); and relative humidity was $20 \%(16-47)$. The mean ( \pm SD) hourly water intake of the ad libitum group was $524 \pm 227 \mathrm{ml}$ • $\mathrm{h}^{-1}$ while the restricted group drank $300 \mathrm{ml} \cdot \mathrm{h}^{-1}$. Considering the mean total fluid intake during the 4-h exercise period the ad libitum group consumed $2.1 \mathrm{~L}$ compared to the $1.2 \mathrm{~L}$ of the restricted group, a difference of $224 \mathrm{ml} \cdot \mathrm{h}^{-1}$ during the $4 \mathrm{~h}$ or a total of $900 \mathrm{ml}$ $[t(57)=P<0.01]$. There were no significant differences between or within groups for either USG or UOsm before or after the exercise period (Table II).

Table III presents the body mass changes and calculated sweat rates of both the ad libitum and restricted intake groups. The differences in the sweat rates between the groups were statistically significant $[t(57)=$ $-4.29, P<0.01]$ while the decrease in body mass was significant for both groups $[t(28)=8.90, P<0.01$ for the ad libitum and $t(27)=13.08, P<0.01$ for the restricted intake group] but not different between groups. Figs. 1 and 2, respectively, present the relationship between the total volume consumed and the post-exercise UOsm and USG for the ad libitum intake group. Figs. 3 and 4, respectively, present the relationship between the change in body mass and UOsm and USG for the ad libitum group. Figs. 5 and $\mathbf{6}$, respectively, present the relationship between the change in body mass and UOsm and USG for the restricted intake group.

Table IV presents the scores for the shooting simulator performance task before and after the march. The ad libitum group showed statistically significantly $[t(57)=$ $-3.30, P<0.01$ ] better scores for their trigger control during the pre-route march task despite the random assignment of the groups. The restricted group improved their trigger control significantly $[t(27)=-2.86, P<$ 0.01 ] after the route march while the ad libitum group showed a non-significant decrease in their performance of this task.

TABLE I. SUBJECT INFORMATION FOR BOTH GROUPS.

\begin{tabular}{|c|c|c|c|}
\hline & Minimum & Mean $( \pm S D)$ & Maximum \\
\hline \multicolumn{4}{|c|}{ Ad Libitum Group $(N=29)$} \\
\hline Years military service & 6.0 & $8.1(1.0)$ & 10.0 \\
\hline Body mass (kg) & 50.4 & $70.6(13.4)$ & 103.2 \\
\hline Stature $(\mathrm{mm})$ & 1594 & $1724(81)$ & 1895 \\
\hline $\begin{array}{l}\text { Predicted } \dot{V}_{\mathrm{O}_{2 \max }} \\
\quad\left(\mathrm{ml} \cdot \mathrm{kg}^{-1} \cdot \mathrm{min}^{-1}\right)\end{array}$ & 24.9 & $36.7(6.8)$ & 50.2 \\
\hline Body fat (\%) & 6.3 & $12.1(4.2)$ & 20.8 \\
\hline Muscle (\%) & 36.7 & $44.6(3.7)$ & 50.1 \\
\hline \multicolumn{4}{|l|}{ Restricted Group $(N=28)$} \\
\hline Years military service & 6.0 & $8.2(1.1)$ & 11.0 \\
\hline Body mass (kg) & 55.2 & $69.3(8.8)$ & 88.4 \\
\hline Stature $(\mathrm{mm})$ & 1600 & $1723(71)$ & 1895 \\
\hline $\begin{array}{l}\text { Predicted } \dot{V}_{\mathrm{O}_{2 \max }} \\
\quad\left(\mathrm{ml} \cdot \mathrm{kg}^{-1} \cdot \mathrm{min}^{-1}\right)\end{array}$ & 26.8 & $37.3(4.4)$ & 46.8 \\
\hline Body fat (\%) & 5.9 & $11.5(3.9)$ & 22.9 \\
\hline Muscle (\%) & 38.7 & $44.2(2.5)$ & 48.1 \\
\hline
\end{tabular}

TABLE II. USG AND UOsm RESULTS FOR BOTH GROUPS PRE- AND POST-EXERCISE.

\begin{tabular}{|c|c|c|c|}
\hline & Minimum & Mean $( \pm \mathrm{SD})$ & Maximum \\
\hline \multicolumn{4}{|l|}{ Restricted Group ( $N=28$ ) } \\
\hline USG (pre-exercise) & 1.010 & $1.020(0.00)$ & 1.025 \\
\hline USG (post-exercise) & 1.015 & $1.021(0.00)$ & 1.025 \\
\hline $\begin{array}{l}\text { UOsm (pre-exercise; } \\
\text { mOsmol } \cdot \mathrm{kg}^{-1} \text { ) }\end{array}$ & 356 & $893(170)$ & 1183 \\
\hline $\begin{array}{l}\text { UOsm (post-exercise; } \\
\text { mOsmol } \cdot \mathrm{kg}^{-1} \text { ) }\end{array}$ & 599 & $878(130)$ & 1141 \\
\hline \multicolumn{4}{|c|}{ Ad Libitum Group $(N=29)$} \\
\hline USG (pre-exercise) & 1.010 & $1.019(0.00)$ & 1.030 \\
\hline USG (post-exercise) & 1.005 & $1.019(0.00)$ & 1.025 \\
\hline $\begin{array}{l}\text { UOsm (pre-exercise; } \\
\text { mOsmol } \cdot \mathrm{kg}^{-1} \text { ) }\end{array}$ & 429 & $868(193)$ & 1242 \\
\hline $\begin{array}{l}\text { UOsm (post-exercise; } \\
\text { mOsmol } \cdot \mathrm{kg}^{-1} \text { ) }\end{array}$ & 84 & 805 (290) & 1173 \\
\hline
\end{tabular}

Table $\mathbf{V}$ presents the observation performance scores for both groups pre- and post-exercise. There were no differences $(P<0.05)$ between the fine motor skill scores for the two groups. The mean $( \pm \mathrm{SD})$ performance time (minutes:seconds) for the pre-exercise fine motor skill scores were 01:23 (00:19) and 01:20 (00:19) for the restricted and ad libitum intake groups, respectively. After the exercise intervention the restricted intake group took 01:18 (00:19) while the ad libitum group required 01:15 (00:15) to complete the task.

\section{DISCUSSION}

Our first relevant finding of this study was that despite a significant $[t(28)=0.57, P<0.01)]$ body mass loss presented by the restricted intake group during exercise $(1.9 \%$ of pre-exercise body mass) the only significant difference between the two groups was the calculated sweat rate during exercise. The sweat rate was significantly higher in the ad libitum group at 762 $\mathrm{ml} \cdot \mathrm{h}^{-1}$ vs. $608 \mathrm{ml} \cdot \mathrm{h}^{-1}[t(57)=-4.29, P<0.01]$. The differences in sweat rates might be attributed to the differences in the water volumes consumed during the march since the ad libitum group ingested on average $900 \mathrm{ml}$ more water during the 4-h route march. Nolte et al. (14) found a significant relationship $\left(P<0.05, \mathrm{r}^{2}=\right.$ 0.92 ) between the rates of fluid intake and of sweating

TABLE III. BODY MASS LOSS AND SWEAT RATE PREDICTION RESULTS FOR BOTH GROUPS PRE- AND POST-EXERCISE.

\begin{tabular}{lccc}
\hline \hline & Minimum & Mean $( \pm$ SD) & Maximum \\
\hline Restricted Group $(\mathrm{N}=28)$ & & & \\
Mass (pre-exercise; kg) & 54.20 & $69.33(8.9)$ & 88.00 \\
Mass (post-exercise; kg) & 53.70 & $67.99(8.7)$ & 86.40 \\
Body mass loss $(\mathrm{kg})$ & 0.50 & $1.34^{*}(0.37)$ & 1.60 \\
Body mass loss $(\%)$ & 0.9 & 1.9 & 2.60 \\
Sweat Rate $\left(\mathrm{ml} \cdot \mathrm{h}^{-1}\right)$ & 395 & $608^{*}(93)$ & 0.755 \\
Ad Libitum Group $(\mathrm{N}=29)$ & & & \\
Mass (pre-exercise; kg) & 50.40 & $70.41(13.3)$ & 102.00 \\
Mass (post-exercise; kg) & 49.30 & $69.36(13.0)$ & 99.90 \\
Body mass loss $(\mathrm{kg})$ & 0.50 & $1.05^{*}(0.77)$ & 2.10 \\
Body mass loss $(\%)$ & 0.9 & 1.5 & 2.0 \\
Sweat Rate $\left(\mathrm{ml} \cdot \mathrm{h}^{-1}\right)$ & 0.489 & $762^{*}(162)$ & 1.189 \\
\hline \hline
\end{tabular}




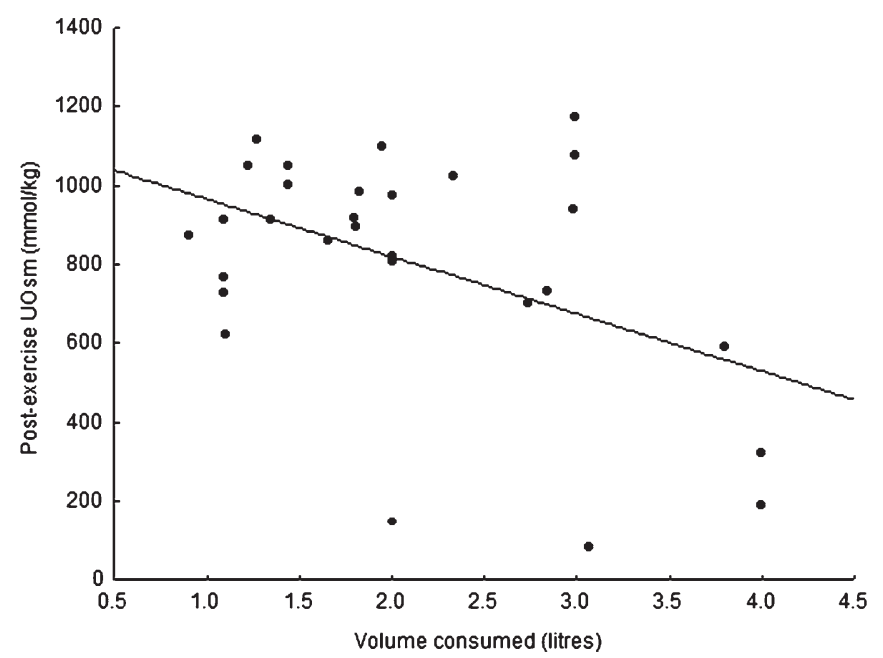

Fig. 1. The relationship between total water intake and urine osmolality for the ad libitum intake group $(N=29)$.

during similar route march exercises. We are unaware of other studies that have evaluated this relationship. Nor do we know whether these variables are causally related (greater fluid intake results in greater sweat loss in order to maintain a safe fluid and electrolyte balance) or explained by their codependence on a third variable, for example, the exercising metabolic rate. Other than this difference, there were no significant differences between the two groups for any of the post-exercise hydration variables that were measured despite differences in body mass loss and total fluid intake. The results, therefore, suggest that despite the significant loss in body mass in the restricted fluid replacement group, drinking $300 \mathrm{ml} \cdot \mathrm{h}^{-1}$ appeared to be comparable to ad libitum drinking for maintaining the soldiers' hydration status. Furthermore, the use of body mass as an indication of hydration status has been questioned in many studies. Three possible reasons why body mass loss during prolonged exercise may not accurately reflect total body water loss includes firstly the production of metabolic

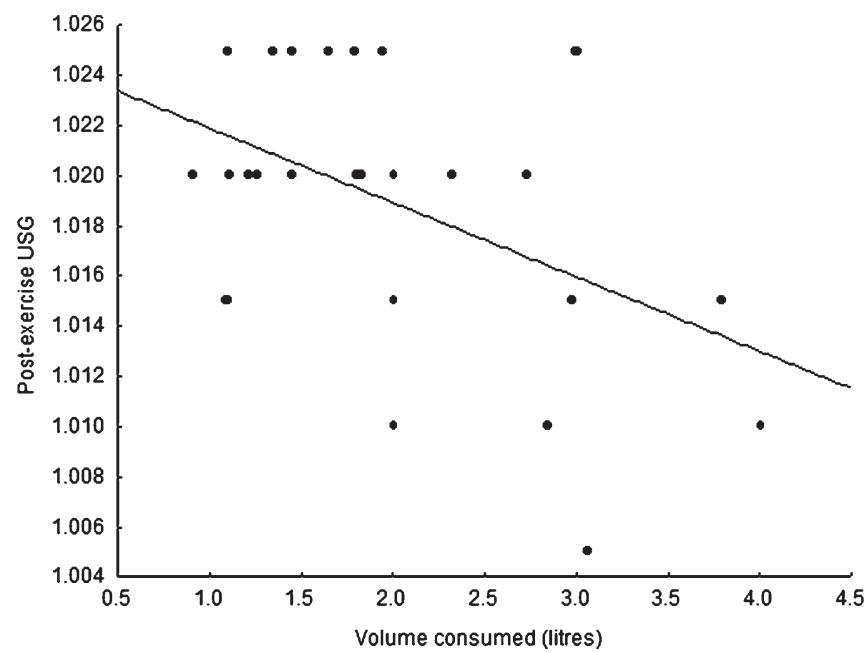

Fig. 2. The relationship between total water intake and urine specific gravity for the ad libitum intake group $(N=29)$.

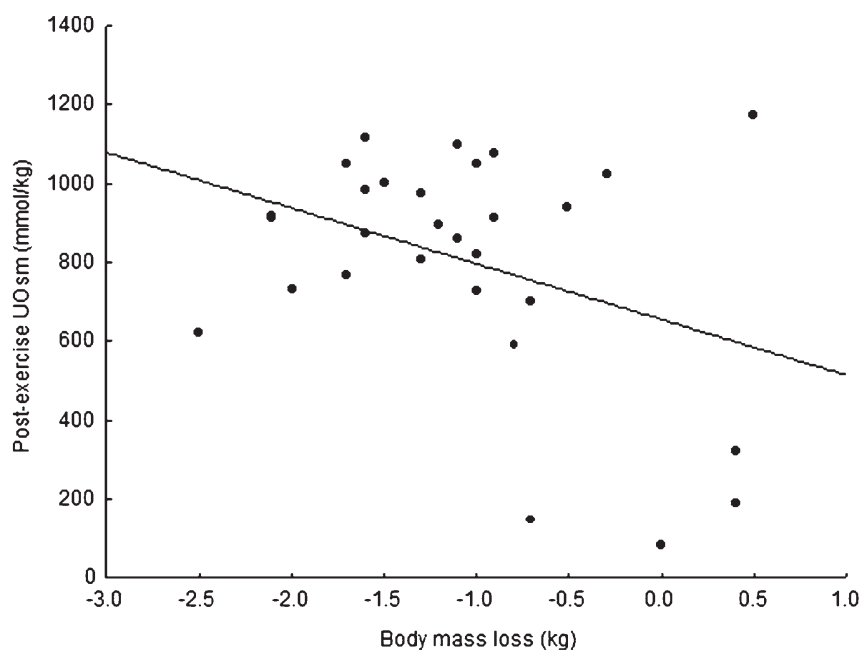

Fig. 3. The relationship between body mass loss and urine osmolality for the ad libitum intake group $(N=29)$.

water during fuel oxidation. A second source of water gain is the intake of exogenous water in the form of either water or the water present in food eaten during exercise. A third theoretical source is the release of water with the breakdown of muscle and liver glycogen (15).

Our second relevant finding was the lack of any significant correlations between the urinary indices and fluid intake or body mass changes, a result now often presented in literature (14) (Figs. 1 to 6). Apart from a non-significant, weak $\left(\mathrm{r}^{2}=0.25\right)$, and medium $\left(\mathrm{r}^{2}=\right.$ $0.67)$ correlation between the post-exercise USG and the post-exercise UOsm for the restricted intake and ad libitum groups, respectively, there were no other significant medium or strong correlations between either USG or UOsm and any other variable, including total fluid intake and body mass loss (Figs. 3 to 6) during the exercise period. Laursen and colleagues also reported that changes in body mass were unrelated to core temperature, plasma sodium concentration, and urine specific gravity in athletes completing a 226-km Ironman Triathlon (10).

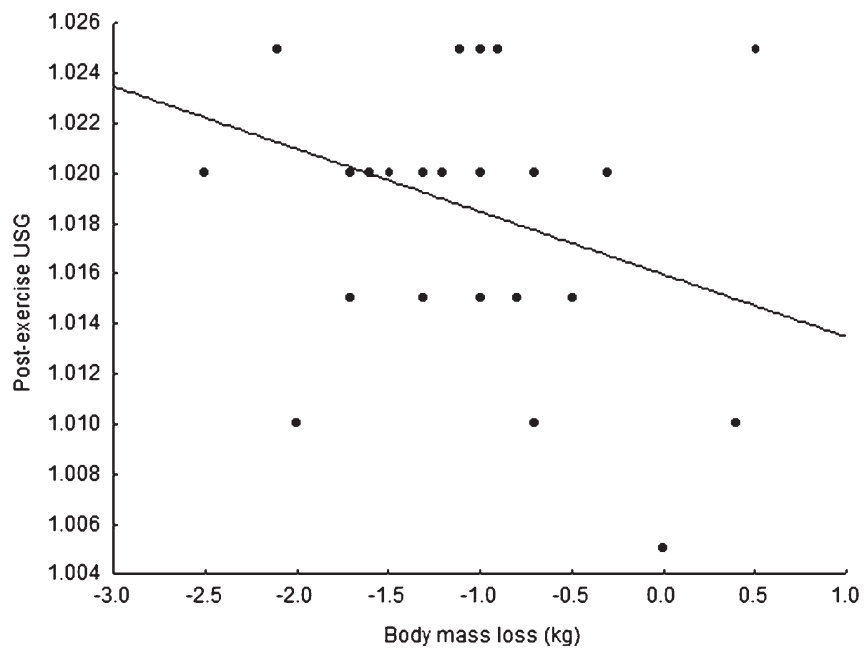

Fig. 4. The relationship between body mass loss and urine specific gravity for the ad libitum intake group $(N=29)$. 


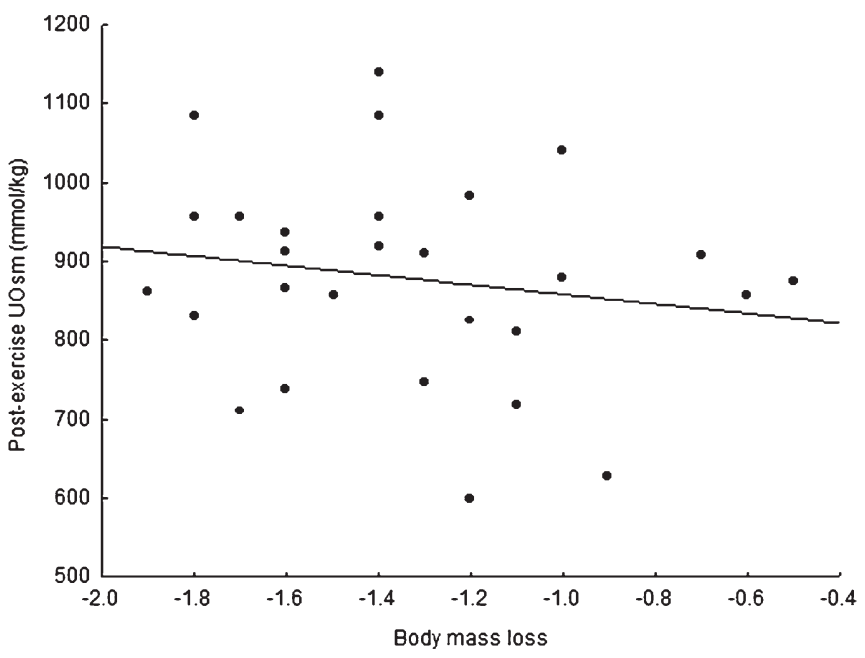

Fig. 5. The relationship between body mass loss and urine osmolality for the restricted intake group $(N=29)$.

The lack of an apparent correlation between these urinary markers and body mass loss and fluid intake could suggest the cautious use of these markers as an accurate assessment of hydration status.

The measurement of total body water (TBW) by means of the diluted isotope technique is considered an accurate method for the determination of hydration status, but unfortunately it is an expensive and laborious technique and, therefore, USG and UOsm are often used to monitor hydration status in field settings (13-15). Despite the finding of this study and others $(10,13,14)$, some still suggest the use of these markers as surrogates for hydration status in exercising humans. According to Armstrong and colleagues, USG and UOsm will both increase with dehydration and are strongly correlated $(4,5)$. It has been proposed that for a "normally" hydrated (euhydrated) person, USG values range from 1.020 to 1.030 while a USG greater than 1.030 represents dehydration (16). Previously, Armstrong and colleagues presented correlation values of $0.96\left(\mathrm{r}^{2}\right)$ (3). However, the

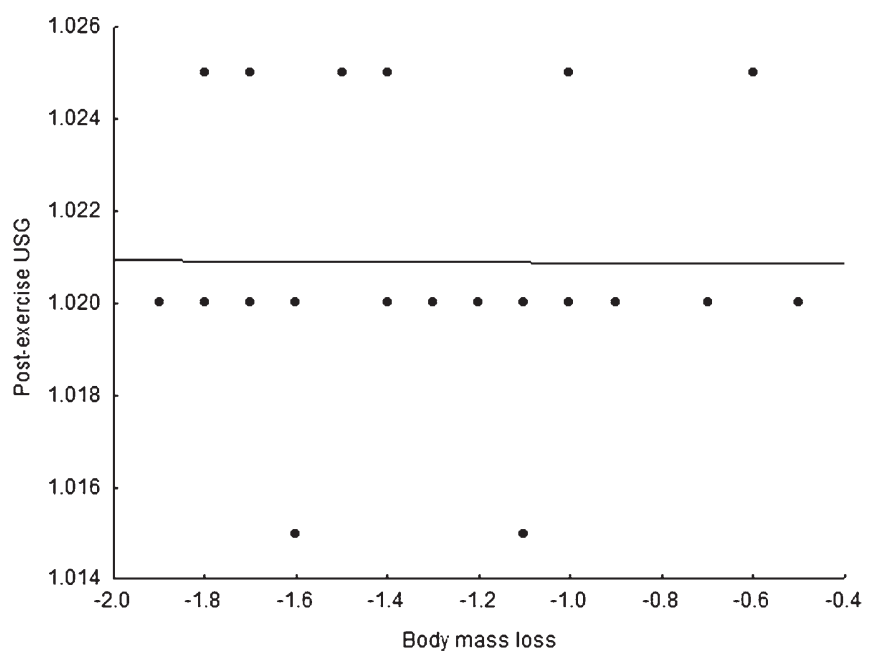

Fig. 6. The relationship between body mass loss and urine specific gravity for the restricted intake group $(N=29)$. results of this study and others argue that urine osmolality is not a good indicator of changes in TBW $(7,13,14,19)$.

Furthermore, both group's mean UOsm fell within a normal range of $300-900 \mathrm{mmol} \cdot \mathrm{kg}^{-1}$; therefore, as with USG, the results suggest that both groups were adequately hydrated. However, we would like to include a caveat against the use of UOsm as an indication of hydration since, in a setting of such variability, there may be no single threshold at which the urine osmolality accurately predicted the hydration status. In addition, urine osmolality is increased when osmotically active solutes are excreted, such as glucose, in patients with uncontrolled diabetes mellitus. For these reasons of high variability, dependence on solute excretion, and lack of correlation with TBW changes, UOsm should be used cautiously as an indicator of hydration status $(9,15)$. Further limitations regarding UOsm may include accuracy issues when used immediately after exercise due to a delay in the renal response, influencing USG and UOsm, and large intercultural differences as evident by mean differences between Germans $\left(860 \mathrm{mmol} \cdot \mathrm{kg}^{-1}\right)$ and Poles $\left(392 \mathrm{mmol} \cdot \mathrm{kg}^{-1}\right)(5,12)$.

In terms of performance measures, results of an intragroup comparison indicates that the restricted intake group presented with better scores in their post-exercise performance measures for all five variables $(P>0.05)$ while the ad libitum group presented with better scores for three $(P>0.05)$ of the variables and a decrease of performance in two. The within group increase of $31 \%$ for the trigger control $[t(27)=-2.86, P<0.01]$ measure and $18 \%$ for the observational task $[t(27)=-3.52, P<$ 0.01] of the restricted intake group were both statistically significant. It should be noted, though, that despite random assignment there was still an initial significant difference in the trigger control measure variable between the groups. Furthermore, the restricted intake group presented with better between group performance scores post-exercises in four of the possible five variables. However, none of these differences were statistically significant. Performance did not, therefore, appear to deteriorate for the restricted intake group; however, it should be noted that the improvements may be attributed to a warm-up effect on coordination as described by Adam and colleagues (1). The results also suggest that aerobic exercise improves some aspects of military task performance since performance in the shooting, observational, and fine motor tasks improved after the exercise bout. Considering the observation task there may well be contributing factors in the improvement in performance such as changes in light contrast due to time of day testing (morning versus afternoon). However, performance did not deteriorate despite the exercise intervention, different fluid replacement strategies, and the completion of a 4-h route march.

Comparison of these results with other published studies is difficult since these tests form part of a custom designed soldier task measurement tool. Recently Adam and colleagues showed that moderate hypohydration of $3 \%$ did not affect cognitive or psychomotor performance 
TABLE IV. SHOOTING SIMULATOR HANDLING, AIMING AND TRIGGER CONTROL TIME RESULTS FOR BOTH GROUPS.

\begin{tabular}{|c|c|c|c|}
\hline & Minimum & Mean $( \pm S D)$ & Maximum \\
\hline \multicolumn{4}{|l|}{ Restricted Group ( $N=28)$} \\
\hline Handling results (pre-exercise) & 15.00 & $60.70(24.2)$ & 88.00 \\
\hline Aiming results (pre-exercise) & 7.00 & $30.37(17.0)$ & 69.00 \\
\hline Aiming results (post-exercise) & 5.00 & $33.22(14.4)$ & 63.00 \\
\hline Trigger control time score (pre-exercise) & 8.00 & $41.33 *(28.1)$ & 86.00 \\
\hline Trigger control time score (post-exercise) & 15.00 & $54.08(23.1)$ & 83.00 \\
\hline Handling results (post-exercise) & 16.00 & $67.26(19.8)$ & 90.00 \\
\hline Aiming results (pre-exercise) & 7.00 & $35.78(17.3)$ & 67.00 \\
\hline Aiming results (post-exercise) & 6.00 & $35.48(15.4)$ & 64.00 \\
\hline Trigger control time score (pre-exercise) & 17.00 & $62.48 *(24.2)$ & 86.00 \\
\hline Trigger control time score (post-exercise) & 8.00 & $60.63(22.6)$ & 86.00 \\
\hline
\end{tabular}

in cold or temperate environments (12). Serwah and Marino investigated the combined effects of hydration and exercise heat stress on choice reaction time. They found that different levels of dehydration produced by different drinking regimes during up to $90 \mathrm{~min}$ of exercise in warm, humid conditions also did not compromise choice reaction time (20). Similarly Szinnai and colleagues showed that dehydration of up to $2.6 \%$ body mass did not alter cognitive-motor function in healthy young subjects (22). In surprising contrast Baker and colleagues found that vigilance-related attention of male basketball players was impaired by dehydration levels ranging between $1-4 \%$, concluding that fluid replacement is essential to prevent a decline in vigilance that occurs with dehydration in highly technically demanding sports (6). Were this finding universally true, we would have expected that performance in one or more of the tests that we performed should have been impaired.

In conclusion, the aim of this study was to compare the effects of an ad libitum and a restricted fluid replacement strategy on selected hydration markers and soldier performance in selected military tasks. We were unable to detect any superiority of the ad libitum drinking regime $\left(525 \mathrm{ml} \cdot \mathrm{h}^{-1}\right)$ compared to the restricted regime. Thus we conclude that a fluid ingestion rate of $300 \mathrm{ml} \cdot \mathrm{h}^{-1}$ could be regarded as an adequate minimum

TABLE V. OBSERVATION SKILL RESULTS FOR BOTH GROUPS.

\begin{tabular}{|c|c|c|c|}
\hline & Minimum & Mean $( \pm \mathrm{SD})$ & Maximum \\
\hline \multicolumn{4}{|l|}{ Restricted Group $(N=28)$} \\
\hline $\begin{array}{l}\text { Number of objects identified } \\
\text { out of possible } 8 \\
\text { (pre-exercise) }\end{array}$ & 3 & $5.96(1.6)$ & 8 \\
\hline $\begin{array}{l}\text { Number of objects identified } \\
\text { out of possible } 8 \\
\text { (post-exercise) }\end{array}$ & 4 & $7.04(1.1)^{*}$ & 8 \\
\hline \multicolumn{4}{|l|}{ Ad Libitum Group $(N=29)$} \\
\hline $\begin{array}{l}\text { Number of objects identified } \\
\text { out of possible } 8 \\
\text { (pre-exercise) }\end{array}$ & 1 & $6.21(1.5)$ & 8 \\
\hline $\begin{array}{l}\text { Number of objects identified } \\
\text { out of possible } 8 \\
\text { (post-exercise) }\end{array}$ & 4 & $7.07(1.1)^{*}$ & 8 \\
\hline
\end{tabular}

$*=P<0.05$. rate of fluid ingestion for male soldiers exercising under conditions similar to those in this study, namely similar exercise durations at equivalent exercise intensity in a moderate, dry climate. However, drinking ad libitum is probably the more appropriate response (13-15), even though there was no measurable benefit associated with this slightly higher rate of fluid intake. A limitation of this study is the accuracy of the use of urinary markers and body mass as an indication of hydration status and it is recommended that the diluted isotope technique also be used to assess changes in total body water during exercise. This technique would be able to relate body mass change to actual total body water changes and could provide significant insight into the efficacy of the different fluid intake regimens (13-15).

\section{ACKNOWLEDGMENTS}

H. W. Nolte would like to thank the Director Technology Development, Department of Defence, South Africa. T. D. Noakes is funded by the University of Cape Town, Medical Research Council, and Discovery Health, and K. Nolte by the University of Pretoria.

Authors and affiliations: Heinrich W. Nolte, Ph.D., ERGOnomics TECHnologies, Armscor Defence Institutes, Pretoria, South Africa; Timothy D. Noakes, M.B.Ch.B., M.D., D.Sc., UCT/MRC Research Unit for Exercise Science and Sports Medicine, University of Cape Town, South Africa; and Kim Nolte, Ph.D., M.A. (HMS) Biokinetics, Department of Biokinetics, Sport and Leisure Sciences, University of Pretoria, South Africa.

\section{REFERENCES}

1. Adam GE, Carter 3rd R, Cheuvront SN, Merullo DJ, Castellani JW, et al. Hydration effects on cognitive performance during military tasks in temperate and cold environments. Physiol Behav 2008; 93:748-56.

2. Adolph EF. Physiology of man in the desert. New York: Interscience Publishers, 1947.

3. Armstrong LE, Maresh CM, Castellani JW, Bergeron MF, Kenefick RW, et al. Urinary indices of hydration status. Int J Sport Nutr 1994; 4:265-79.

4. Armstrong LE, Soto JA, Hacker FT Jr, Casa JR, Kavouras SA, Maresh CM. Urinary indices during dehydration, exercise, and rehydration. Int J Sport Nutr 1998; 8:345-55.

5. Armstrong LE. Hydration assessment techniques. Nutr Rev 2005; 63(6, Pt. 2):S40-54.

6. Baker LB, Conroy DE, Kenney WL. Dehydration impairs vigilance-related attention in male basketball players. Med Sci Sports Exerc 2007; 39:976-83.

7. Hackney AC, Coyne JT, Pozos R, Feith S, Seale J. Validity of urineblood hydrational measures to assess total body water changes during mountaineering in the sub-Arctic. Arctic Med Res 1995; 54:69-77. 
8. Harriss DJ, Atkinson G. Ethical standards in sport and exercise science research. Int J Sports Med 2009; 30:701-2.

9. Institute of Medicine of the National Academies. Dietary references intakes for water, potassium, sodium, chloride, and sulfate. Washington, DC: The National Academic Press; 2004.

10. Laursen PB, Suriano R, Quod MJ, Lee H, Abbiss CR, et al. Core temperature and hydration status during an Ironman triathlon. Br J Sports Med 2006; 40:320-5.

11. Léger LA, Lambert J. A maximal multistage 20-m shuttle run test to predict $\mathrm{VO}_{2 \max }$. Eur J Appl Physiol Occup Physiol 1982; 49:1-12.

12. Manz F, Wentz A. 24-h hydration status: parameters, epidemiology and recommendations. Eur J Clin Nutr 2003; 57(Suppl. 2):S10-8.

13. Nolte H, Noakes TD, van Vuuren B. Ad libitum fluid replacement in military personnel during a 4-h route march. Med Sci Sports Exerc 2010; 42:1675-80.

14. Nolte HW, Noakes TD, van Vuuren B. Protection of total body water content and absence of hyperthermia despite $2 \%$ body mass loss ("voluntary dehydration") in soldiers drinking ad libitum during prolonged exercise in cool environmental conditions. Br J Sports Med 2011; 45:1106-12.

15. Nolte HW, Noakes TD, van Vuuren B. Trained humans can exercise safely in extreme dry heat when drinking water ad libitum. J Sports Sci 2011; 29:1233-41.
16. Popowski LA, Oppliger RA, Lambert GP, Johnson KA, Gisolf $\mathrm{CV}$. Blood and urinary measures of hydration status during progressive acute dehydration. Med Sci Sports Exerc 2001; 33:747-53.

17. Ross WD, Marfell-Jones MJ. Kinanthropometry. In: MacDougall JD, Wenger HA, Green HJ. Physiological testing of the highperformance athlete, 2nd ed. Champaign, IL: Human Kinetics Books; 1991.

18. RTO-MP-HFM-086. Maintaining hydration: issues, guidelines, and delivery. RTO meeting proceedings. RTO Human Factors and Medicine Panel (HFM) Specialists'Meeting held in Boston, MA; December 10-11, 2003. Neuilly-sur-Seine, France: NATO; 2003.

19. Ruby BC, Schoeller DA, Sharkey BJ, Burks C, Tysk S. Water turnover and changes in body composition during arduous wildfire suppression. Med Sci Sports Exerc 2003; 35:1760-5.

20. Serwah N, Marino FE. The combined effects of hydration and exercise heat stress on choice reaction time. J Sci Med Sport 2006; 9:157-64.

21. Statsoft Statistica. Tulsa, OK: Statsoft, Inc.; 2000.

22. Szinnai G, Schachinger H, Arnaud MJ, Linder L, Keller U. Effect of water deprivation on cognitive-motor performance in healthy men and women. Am J Physiol Regul Integer Comp Physio $2005 ; 289: 275-80$. 


\section{Author Query sheet-ASEM3378}

Q1 : Author: Please provide the city in South Africa where Davis Health is located.

Q2 : Author: This sentence ("Calculated sweat rates were not corrected ...") has been rewritten for clarity. Does it still say what you were trying to say? Is this correct? 